Journal for ImmunoTherapy of Cancer

\section{Short-course IL-15 given as a continuous infusion led to a massive expansion of effective NK cells: implications for combination therapy with antitumor antibodies}

To cite: Dubois SP,

Miljkovic MD, Fleisher TA, et al. Short-course IL-15 given as a continuous infusion led to a massive expansion of effective NK cells: implications for combination therapy with antitumor antibodies. Journal for ImmunoTherapy of Cancer 2021;9:e02193. doi:10.1136/ jitc-2020-002193

- Additional material is published online only. To view, please visit the journal online (http://dx.doi.org/10.1136/jitc2020-002193).

SPD and MDM contributed equally.

TAW and KCC contributed equally.

Accepted 16 March 2021
Check for updates

(C) Author(s) (or their employer(s)) 2021. Re-use permitted under CC BY-NC. No commercial re-use. See rights and permissions. Published by BMJ.

For numbered affiliations see end of article.

Correspondence to Dr Thomas A Waldmann; tawald@mail.nih.gov

\section{ABSTRACT}

Background Full application of cytokines as

oncoimmunotherapeutics requires identification of optimal regimens. Our initial effort with intravenous bolus recombinant human interleukin-15 (rhlL-15) was limited by postinfusional reactions. Subcutaneous injection and continuous intravenous infusion for 10 days (CIV-10) provided rhlL-15 with less toxicity with CIV-10 giving the best increases in $\mathrm{CD}^{+}$lymphocytes and natural killer (NK) cells. To ease rhlL-15 administration, we shortened time of infusion. Treatment with rhlL-15 at a dose of $3-5 \mu \mathrm{g} / \mathrm{kg}$ as a 5-day continuous intravenous infusion (CIV-5) had no dose-limiting toxicities while effector cell stimulation was comparable to the CIV-10 regimen.

Methods Eleven patients with metastatic cancers were treated with rhIL-15 CIV-5, $3 \mu \mathrm{g}(\mathrm{n}=4), 4 \mu \mathrm{g}(\mathrm{n}=3)$, and 5 $\mu \mathrm{g} / \mathrm{kg} /$ day $(\mathrm{n}=4)$ in a phase I dose-escalation study (April 6, 2012).

Results Impressive expansions of NK cells were seen at all dose levels (mean 34-fold), including CD56 bright NK cells (mean 144-fold for $4 \mu \mathrm{g} / \mathrm{kg}$ ), as well as an increase in $\mathrm{CD}^{+} \mathrm{T}$ cells (mean 3.38 -fold). At $5 \mu \mathrm{g} / \mathrm{kg} /$ day, there were no dose-limiting toxicities but pulmonary capillary leak and slower patient recovery. This led to our choice of the $4 \mu \mathrm{g} / \mathrm{kg}$ as CIV- 5 dose for further testing. Cytolytic capacity of CD56 bright and CD56 $6^{\text {dim }}$ NK cells was increased by interleukin-15 assayed by antibody-dependent cellular cytotoxicity (ADCC), natural cytotoxicity and natural killer group 2D-mediated cytotoxicity. The best response was stable disease.

Conclusions IL-15 administered as CIV- 5 substantially expanded NK cells with increased cytotoxic functions. Tumor-targeting monoclonal antibodies dependent on ADCC as their mechanism of action including alemtuzumab, obinutuzumab, avelumab, and mogamulizumab could benefit from those NK cell expansions and provide a promising therapeutic strategy.

Trial registration numbers NCT01572493, NCT03759184, NCT03905135, NCT04185220 and NCT02689453.

\section{INTRODUCTION}

Since the Food and Drug Administration approval of interleukin (IL)-2 and interferon alpha for the treatment of patients with cancer, diverse cytokines have been evaluated for the treatment of neoplasia. ${ }^{1-3}$ However, for cytokines to play a major role in cancer therapy, novel strategies for their use will have to be developed. Determination of the optimal treatment regimen is essential for the development of cytokines as cancer immunotherapeutics. IL-15, a pleiotropic cytokine that stimulates the differentiation and proliferation of natural killer (NK) and CD8 $\mathrm{T}$ cells, is among the cytokines showing promise. ${ }^{4-17}$ IL-15 signals through a heterotrimeric receptor including the common gamma chain $\left(\gamma_{c}\right)$ shared with IL-2, IL-4, IL-7, IL-9 and IL-21, the beta chain shared with IL-2 and a unique IL-15R $\alpha$ chain. ${ }^{4} 1415$ IL-15R $\alpha$ and IL-15 are produced in a coordinated fashion predominantly by activated monocytes and dendritic cells. ${ }^{4}$ 14-16 Stimulation of these cells with type I or type II interferon through agonistic CD40 ligands or toll-like receptor agonists induces the synchronized expression of IL-15 and IL-15R $\alpha .^{18-20}$ IL-15 is secreted only in small quantities and is mainly membrane bound under physiological conditions $^{5}$. IL-15 bound to IL-15R $\alpha$ is presented at an immunological synapse in trans to cells that express IL-2/IL-15R $\beta$ and $\gamma_{c}$ but minimal IL-15R $\alpha .^{5}{ }^{21-23}$ Such IL-2/IL-15R $\beta$ $\gamma_{c}$ expressing target cells stimulated by the IL-15/IL-15R $\alpha$ pair include NK and CD8 ${ }^{+}$ $\mathrm{T}$ cells. In contrast to IL-2, IL-15 inhibited IL-2-mediated activation-induced cell death (AICD), less consistently activated Tregs and did not cause a significant capillary leak 
syndrome in mice or non-human primates. ${ }^{42}$ The ability of IL-15 to activate crucial effector T and NK cells, its inhibition of AICD and its capacity to maintain function of CD8 memory T cells provided the scientific basis for evaluation of IL-15 as a cancer immunotherapeutic. IL-15 demonstrated activity in syngeneic murine transgenic adenocarcinoma mouse prostate C2 prostatic cancer, Pmel-1, B16 melanoma and MC38 and CT26 colon carcinoma models. ${ }^{12} 1325-29$

On the basis of these observations, an Escherichia coli recombinant DNA-based process was developed to provide clinical grade recombinant human interleukin-15 (rhIL-15) that ultimately produced a non-glycosylated, single-chain peptide of 150 amino acids with a calculated molecular weight of 12901 Dc.

The different dose, dosing and formulation strategies employed with IL-15 can be compared in terms of the magnitude of expansion of total NK cells, in particular the $\mathrm{CD} 56^{\text {bright }} \mathrm{NK}$ subset, and $\mathrm{CD} 8^{+} \mathrm{T}$ cells achieved with doses with acceptable toxicity. Postinfusional reactions limited dose escalation and immune activation in the first-in-human clinical trial of rhIL-15 given as a $30 \mathrm{~min}$ intravenous bolus (IVB) daily for 12 days. ${ }^{16}$ At the maximum tolerated dose (MTD) of 0.3 $\mu \mathrm{g} / \mathrm{kg} /$ day, the maximum increase in total NK cells was twofold to threefold. Ten-day subcutaneous (MondayFriday for two consecutive weeks) and 10-day continuous intravenous infusion (CIV) were better tolerated and produced greater stimulation of effector NK and CD $8^{+} \mathrm{T}$ cells than IVB. ${ }^{30}$ At the MTD of $2 \mu \mathrm{g} / \mathrm{kg} /$ day, there was a mean 10.8-fold increase maximum for NK cells, 37-fold for CD56 $6^{\text {bright }}$ NK cells and 3.3-fold for $\mathrm{CD}^{+} \mathrm{T}$ cells when rhIL-15 was administered subcutaneously. The third trial of rhIL-15 involved a continuous intravenous infusion for 10 days (CIV-10) with the MTD concluded to be $2 \mu \mathrm{g} / \mathrm{kg} /$ day. ${ }^{31} \mathrm{CIV}-10$ infusions of rhIL-15 resulted in the most dramatic increases in circulating effector cells-with a mean 38-fold increase in total NK cells, 358-fold increase in CD56 $6^{\text {bright }} \mathrm{NK}$ cells and a 5.8-fold increase in $\mathrm{CD}^{+} \mathrm{T}$ cells. ${ }^{31}$ Lytic functions of both NK subsets were augmented. Stable disease was the best response in these trials, leading to the conclusion that for IL-15 to play a major role in cancer therapy, it would have to be used in combination trials. As NK cells are the main mediators of antibodydependent cellular cytotoxicity (ADCC), combination trials will pair rhIL-15 with antitumor monoclonal antibodies which function through ADCC. In the present study, to increase patient and physician acceptance, a short course of IL-15 (5 days) was given as a CIV. We report the results of this 5-day continuous intravenous infusion (CIV-5) rhIL-15 regimen that had a safety profile and stimulation of effector cells comparable to CIV-10 and with doses up to $5 \mu \mathrm{g} / \mathrm{kg} /$ day without doselimiting toxicities.

In addition to providing a more patient and physician acceptable duration of 5 days, in figures $1-3$, we provide major insights concerning the impact of IL-15 on the strong proliferation and phenotypical changes of NK cells induced by CIV-5. Our study includes the effects on the major activating and inhibitory receptors expressed by the NK subsets ${ }^{\text {bright }}$ and CD56 $6^{\mathrm{dim}}$ cells following IL-15 infusions. We provide data on IL-15 infusions augmenting cytokine production and cytokine function of both NK-cell subsets. Furthermore, we provide new data on the impact of IL-15 infusions on the induction, expansion, and effect of cytokine production on T-cell subsets.

\section{MATERIALS AND METHODS}

Additional information is provided in online supplemental file 1 .

\section{Recombinant human interleukin-15}

rhIL-15 was produced in E. coli as previously reported. ${ }^{16}$

\section{Patients and study design}

Patients with advanced metastatic solid tumors for whom standard curative or palliative treatments did not exist were enrolled in this single-center, non-randomized, phase I trial to determine the safety and toxicity of IL-15 (online supplemental table 1). As inpatients, patients received rhIL-15 by CIV for five consecutive days. IL-15 cycles were repeated every 3 weeks. The study used a $3+3$ interpatient dose-escalation design administering doses at 3,4 and $5 \mu \mathrm{g} / \mathrm{kg} /$ day. Treatments continued until tumor regression or two cycles if the best response was stable disease. Evaluation of the MTD was limited to the first cycle, but overall tolerability of the regimen was considered in the selection of the dose for further study (see online supplemental methods).

\section{Investigational treatment}

rhIL-15 was produced under current good manufacturing practice conditions in an E. coli expression system, as described previously. ${ }^{16}$

The rhIL-15 was delivered intravenously by infusion or ambulatory pump for five consecutive days (120 hours). The bags containing IL-15 were changed daily. The rhIL-15 was diluted to a concentration of $1 \mu \mathrm{g} / \mathrm{mL}$ with $0.1 \%$ human serum albumin to improve stability and was administered by CIV at doses of 3,4 , and $5 \mu \mathrm{g} / \mathrm{kg} /$ day for 5 days.

\section{Clinical assessment}

Patients had regular measurement of vital signs, oral intake and output, physical examination, and daily chemistry and hematology laboratories. We performed staging CT scans and/or other appropriate radiographical procedures to evaluate their disease after the even-numbered cycles. Antitumor responses were assessed by RECIST V.1.1 criteria. $^{32}$ 

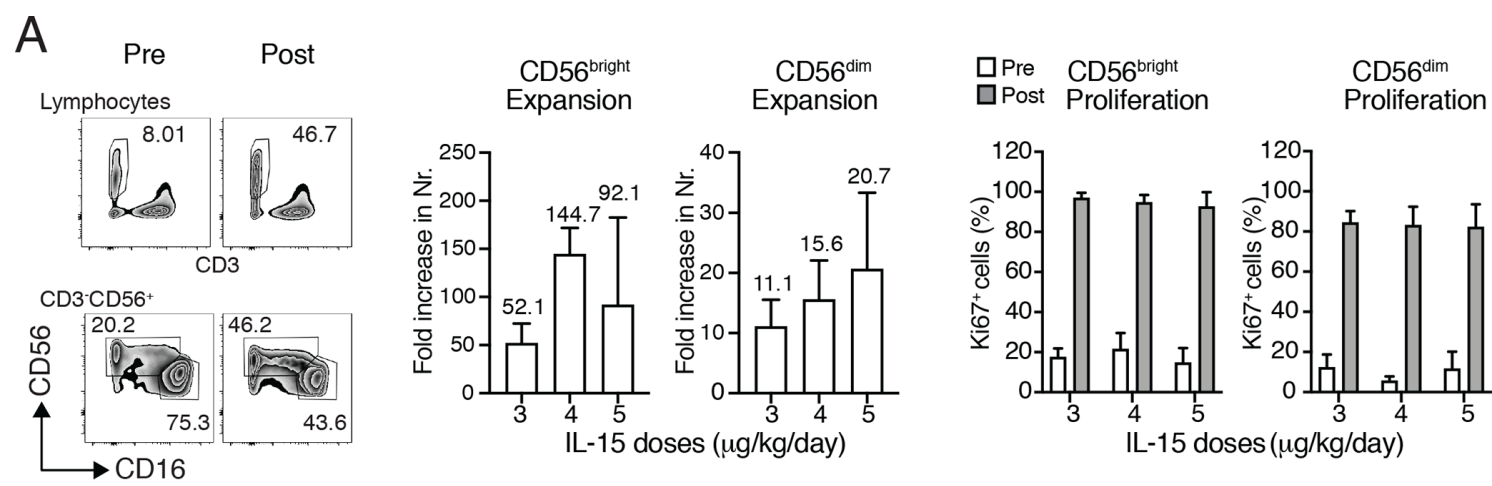

B

$\square$ Pre
$\square$ Post $\quad$ Activating receptors

CD16

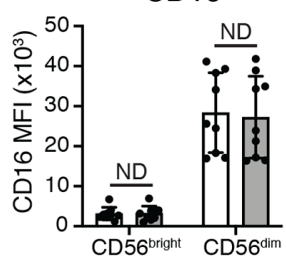

NKp46/CD335

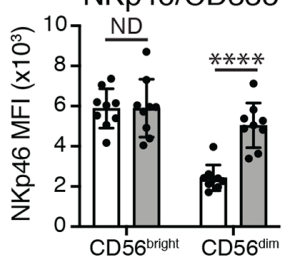

NKp30/CD337

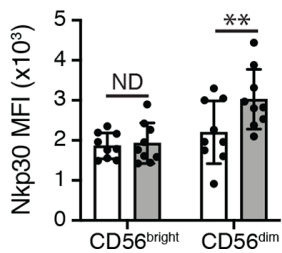

NKG2D/CD314

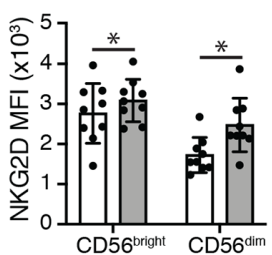

CD122

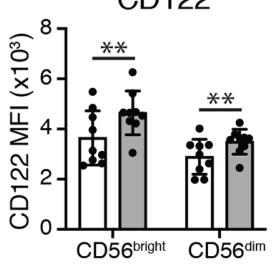

DNAM-1/CD226

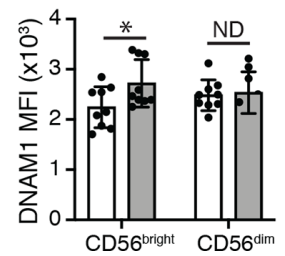

Inhibitory receptors
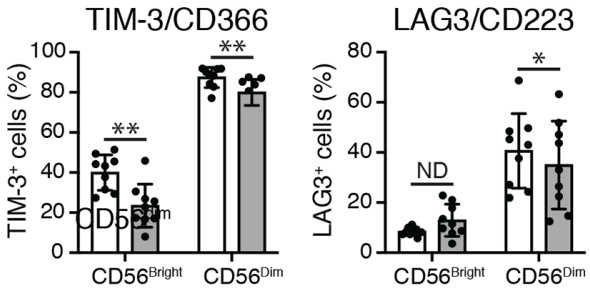

CTLA-4/CD152
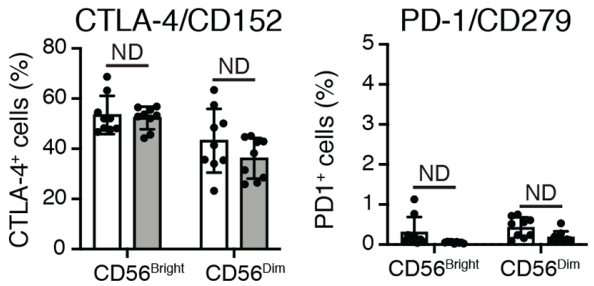

TIGIT

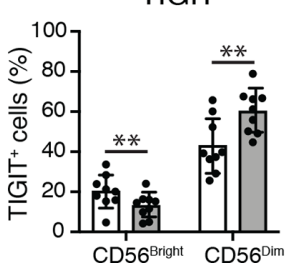

Figure 1 Strong proliferation and phenotypical changes of NK cells induced by CIV-5. (A,B) Analyses of the two major NK-cell subsets, CD56 bright and CD56 ${ }^{\text {dim }}$, comparing their percentages, numbers and phenotypes before and 3 days after the end of IL-15 infusions. (A) Left panels show an example of percentages of NK cells among PBMCs (top) and percentages of both NK subsets, CD56 bright and CD56 ${ }^{\text {dim }}$ cells (bottom), prior to and after IL-15 infusions. Middle graphs depict fold increases of each NK subset following IL-15 treatment (three patients/dose). Right graphs display percentages of the proliferation marker Ki67 expressed among each NK subset prior to and after IL-15 infusions (three patients/dose). No statistical differences have been observed among the three different doses of IL-15. (B) Phenotypical changes of NK-cell subsets following IL-15 treatment. Left: graphs show MFI of the major activating receptors expressed by NK cells. Changes in expressions of those activating markers differed between NK subsets. Expressions of NKp46, NKp30, NKG2D and CD122 were increased on CD56 ${ }^{\text {dim }}$ cells. Augmentations in the surface expressions of NKG2D, CD122 and DNAX accessory molecule 1 (DNAM1) were observed on CD56 bright cells. Right: graphs depict percentages among each NK subset expressing surface proteins involved in inhibition or exhaustion of NK cells. IL-15 appears to have opposite effects on percentages of cells expressing TIGIT with their decreases in CD56 ${ }^{\text {bright }}$ cells and their increases on CD56 ${ }^{\text {dim }}$ cells. Decreased percentages of TIM- $3^{+}$cells were detected in both NK subsets as well as $\mathrm{LAG}^{+}$among the CD56 ${ }^{\mathrm{dim}}$ subset. Analyses were done using nine patients (three patients/dose). ${ }^{*} \mathrm{P}<0.05,{ }^{* *} \mathrm{P}<0.01$, ${ }^{* * * *} \mathrm{P}<0.0001$. IL, interleukin; $\mathrm{LAG3}^{+}$, lymphocyte-activation gene 3; MFI, mean fluorescence intensity; ND, no difference; NK, natural killer; NKG2D, natural killer group 2D; PBMC, peripheral blood mononuclear cell; TIGIT, T-cell immunoreceptor with Ig and ITIM domains; TIM-3', T-cell immunoglobulin and mucin domain containing 3.

\section{Correlative laboratory analyses}

Fluorescence-activated cell sorting (FACS) analysis

Blood samples were taken on day 1, just prior to treatment, and on day 8 , which was the expected time of maximum lymphocytosis. Peripheral blood mononuclear cells (PBMCs) were purified via Ficoll centrifugation and 
A
CD56 bight

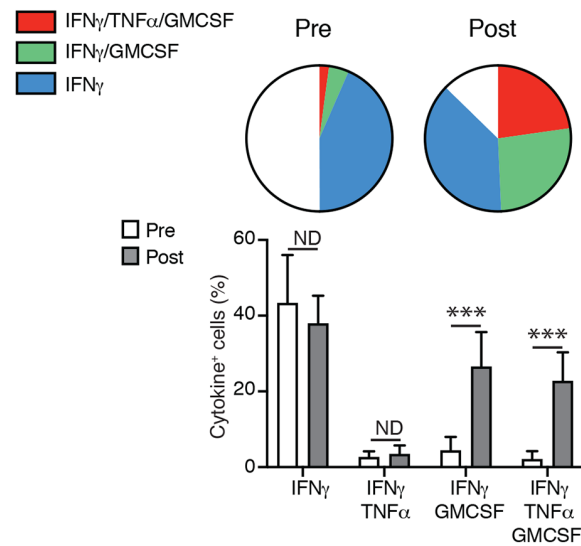

$\mathrm{IL}-12 / \mathrm{IL}-18$

CD56 dim
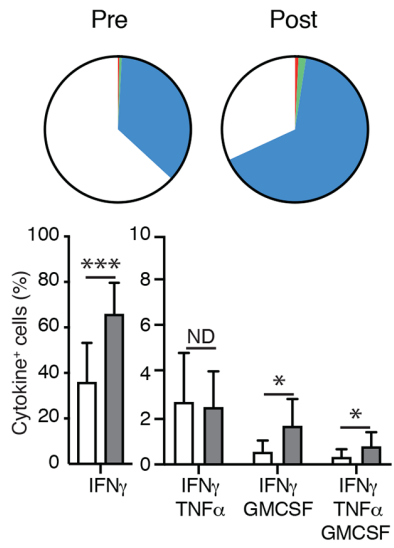
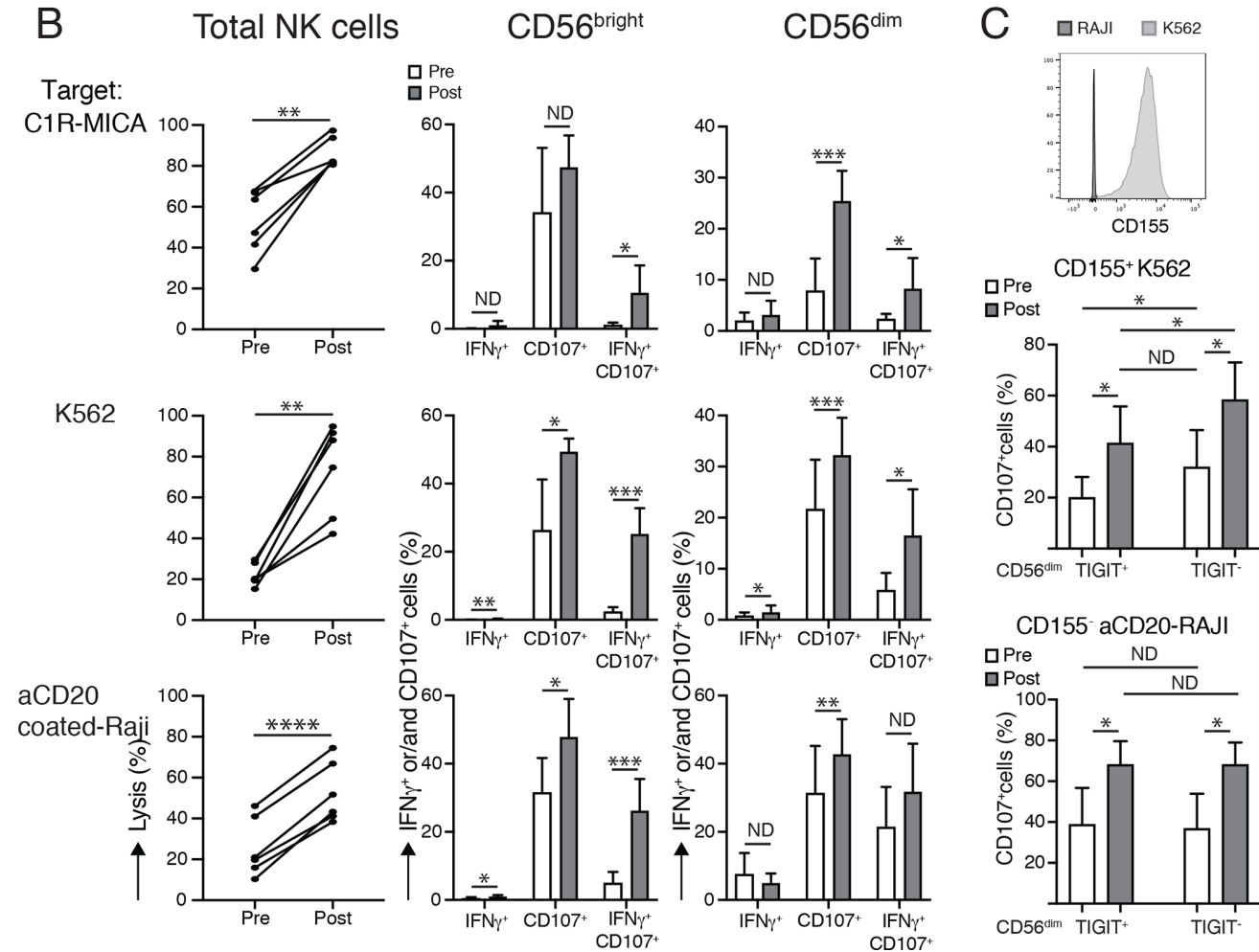

Figure 2 II-15 infusions augment cytokine production and cytotoxic functions of both NK-cell subsets. (A) IL-15 treatments intensify cytokine productions by NK subsets. Top: depicts a schematic view and bottom graphs detail analyses of the major changes in cytokine productions by following intracellular detections of IFN- $\gamma$, TNF- $\alpha$ and GM-CSF by each NK subset when PBMCs were stimulated with IL-12 and IL-18. After treatments, two different subpopulations among CD56 ${ }^{\text {bright }}$ subset emerged: one subpopulation was able to secrete the three cytokines, whereas the second subpopulation coproduced IFN- $\gamma$ and GMCSF. For the CD56 ${ }^{\text {dim }}$ subset, only percentages of cells releasing IFN- $\gamma$ increased after IL-15 infusions. (B) IL-15 treatments increase cytotoxic functions of both NK subsets. Left graphs compare lytic activities of same numbers of total NK cells prior to and after treatment at an effector: target ratio of 5:1 against three different target cells involving various activating receptors. Middle graphs (CD56 ${ }^{\text {bright }} \mathrm{NK}$ cells) and right graphs (CD56 ${ }^{\text {dim }} \mathrm{NK}$ cells) depict degranulation assessed via CD107 detection and intracellular IFN- $\gamma$ production induced by stimulation with the same target cells at an effector: target ratio of $2: 1$. In the CD56 ${ }^{\text {bright }}$ NK subset, IL-15 treatments supported cells having abilities to degranulate and produce IFN- $\gamma$ at the same time, whereas in CD56 ${ }^{\text {dim }}$ NK subset cells gained mainly in degranulation on target recognition. (C) IL-15 infusions increase targetinduced degranulation despite TIGIT-mediated inhibition. Top histogram displays TIGIT ligand expression, CD155, on K562 and Raji target cells. Middle and bottom graphs compare percentages of CD107 upregulation among TIGIT $^{+}$and TIGIT $^{-}$CD56 $^{\text {dim }}$ NK $^{-1}$ subsets on CD155 $5^{+} \mathrm{K} 62$ (middle graph) and CD155- aCD20Raji (bottom graph) stimulations prior and after IL-15 treatments. Although TIGIT $^{+}$CD56 ${ }^{\text {dim }}$ subset had lower abilities to degranulate than TIGIT- CD56 $^{\text {dim }}$ cells when target cells express CD155, their CD107 percentages augmented after IL-15 infusions. Analyses were done using six patients (two patients/dose of IL15 tested). ${ }^{*} \mathrm{P}<0.05,{ }^{* *} \mathrm{P}<0.01$, ${ }^{* \star *} \mathrm{P}<0.001$, ${ }^{* \star *} \mathrm{P}<0.0001$. GM-CSF, granulocyte-macrophage colony-stimulating factor; IFN- $\gamma$, interferon gamma; IL, interleukin; ND, no difference; PBMC, peripheral blood mononuclear cell; TIGIT, T-cell immunoreceptor with Ig and ITIM domains; TNF- $\alpha$, tumor necrosis factor alpha. 
A

Expansion

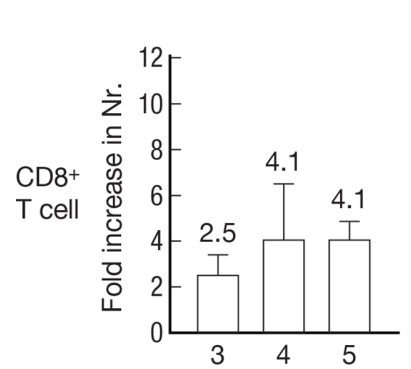

IL-15 doses $(\mu \mathrm{g} / \mathrm{kg} /$ day $)$

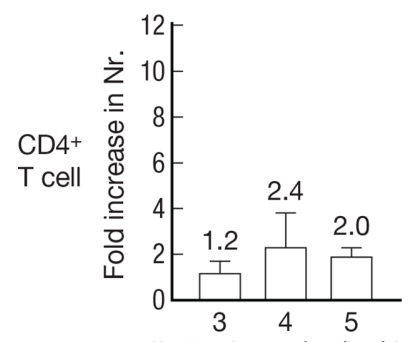

IL-15 doses $(\mu \mathrm{g} / \mathrm{kg} /$ day $)$
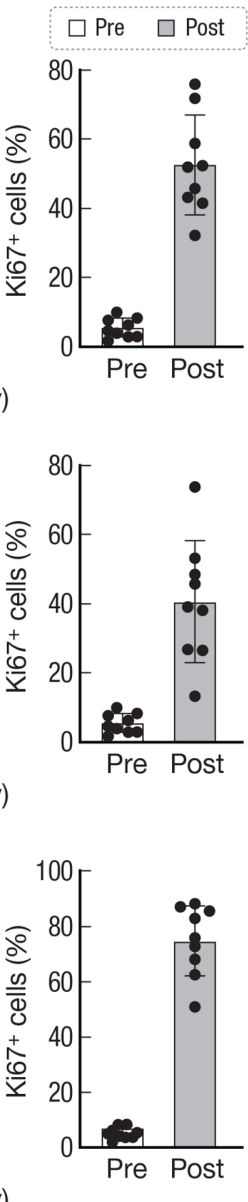

B
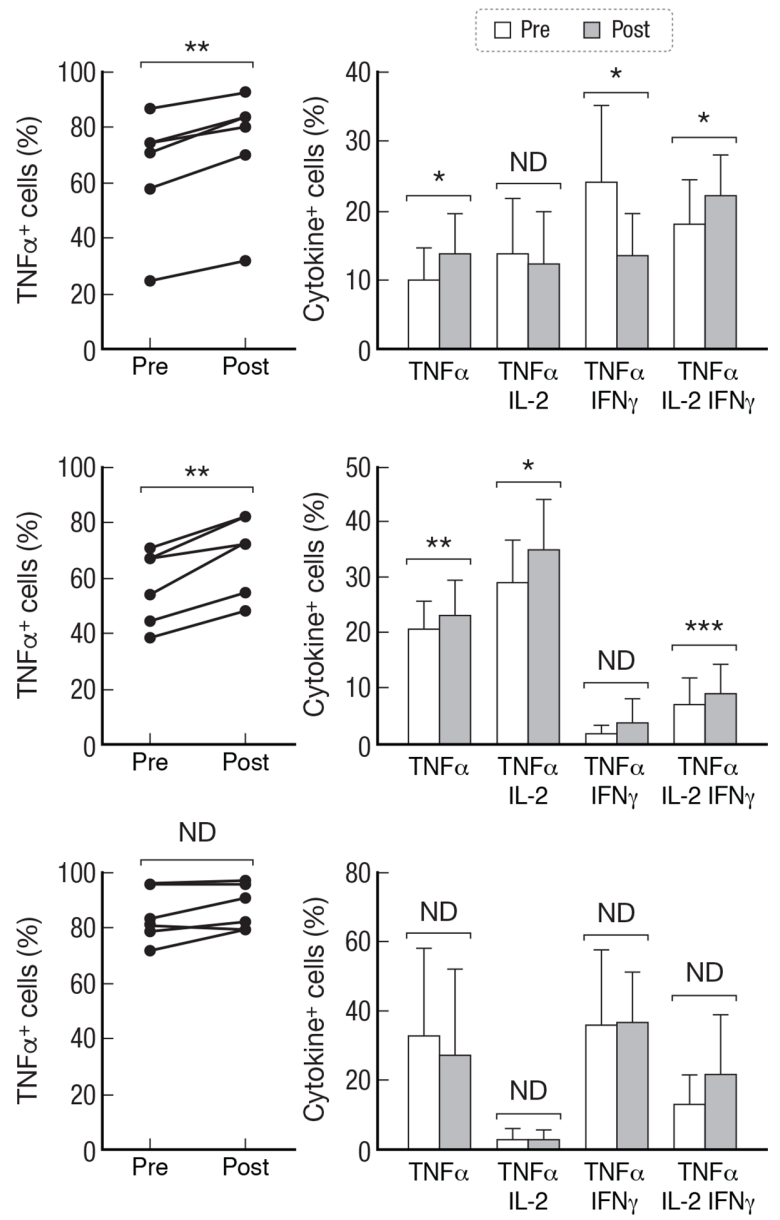

Figure 3 IL-15 infusions induce expansions and affect cytokine production in T-cell subsets. (A) Fold increases, proliferations with detection of Ki-67 in $\mathrm{CD}^{+}$cells, $\mathrm{CD} 4^{+}$cells and $\gamma \delta \mathrm{T}$ cells obtained after analyses of samples frozen prior and 3 days after the end of IL-15 infusions. No statistical differences were observed among the three different doses of IL-15. (B) Comparison of TNF- $\alpha$, IFN- $\gamma$ and IL-2 production in each T-cell subset prior and after treatments following PMA/ionomycin stimulation. No change was observed within $\gamma \delta$ T cells. Both $C D 8^{+}$and $C D 4^{+} T$ cells gained in their abilities to secrete TNF- $\alpha .{ }^{*} \mathrm{P}<0.05,{ }^{* \star}$ $\mathrm{P}<0.01$, ${ }^{\star * \star} \mathrm{P}<0.001$. IFN- $\gamma$, interferon gamma; IL, interleukin; ND, no difference; PMA, Phorbol 12-myristate 13-acetate; TNF- $\alpha$, tumor necrosis factor alpha.

viably frozen at $15 \times 10^{6}$ cells per vial. After thawing, PBMCs were rested overnight at $37^{\circ} \mathrm{C}$ in $\mathrm{RPMI} / 10 \%$ human $\mathrm{AB}$ serum (MediaTech).

Antibodies used are listed in online supplemental table 2. PBMCs were blocked with human TruStain FcX BioLegend for $15 \mathrm{~min}$ at room temperature and stained with antibodies recognizing surface proteins $(45 \mathrm{~min}$ at $4^{\circ} \mathrm{C}$ ). Cells were permeabilized with Transcription Factor Fixation Permeabilization (eBioscience) to stain Ki-67. Stains for intracellular proteins were done with the provided buffers (30 min RT). Analyses were done with FACS Verse. Choices for gating strategies to distinguish NK CD56 $6^{\text {bright }}$ and CD56 $6^{\text {dim }}$ NK-cell subsets are described in online supplemental figure 4.

\section{Ex vivo activations}

For cytokine production analyses, thawed and rested PBMCs were stimulated with PMA (5 ng/mL, Sigma) plus ionomycin (500 nmol/L, Sigma), or with human IL-12
(10 ng/mL, PeproTech) plus human IL-18 (50 ng/mL, R\&D Systems). Alternatively, PBMCs were exposed to the target cell lines K562 (ATCC CCL-243), MHC class I chain-related protein A (C1R-MICA) MHC class I related stress-inducible surface glycoprotein (kindly provided by $\mathrm{Dr}$ Veronika Groh-Spies, Fred Hutchinson Cancer Research Center) or to anti-CD20-coated Raji (ATCC CCL-86) cells that had been preincubated with $10 \mu \mathrm{g} / \mathrm{mL}$ of the antibody $\left(30 \mathrm{~min}\right.$ at $4^{\circ} \mathrm{C}$ ) and washed. Stimulation and coincubations were done for 5 hours at $37^{\circ} \mathrm{C}$ with brefeldin A present during the last 4 hours.

\section{Cytotoxicity assays}

Cytotoxicity assays were performed as described previously. ${ }^{33}$ K562, anti-CD20-coated Raji, and C1R-MICA were used as target cells and uncoated Raji as control cells. Target and control cells were labeled at different carboxyfluorescein succinimidyl ester concentrations (1 vs $0.1 \mu \mathrm{mol} / \mathrm{L}$, Invitrogen). Target and control cells were 
mixed at equal numbers and added to various numbers of NK cells. Incubations were done in the presence of human IL-15 (2 ng/mL, 18 hours at $\left.37^{\circ} \mathrm{C}\right)$. The ratios of surviving propidium iodide-negative target and control cells with or without NK-cell exposures were determined by FACS and used to calculate the percentages of target cell lysis with the formula $100-\mathrm{T}_{\mathrm{NK}} / \mathrm{C}_{\mathrm{NK}} \div \mathrm{T}_{\mathrm{CON}} / \mathrm{C}_{\mathrm{CON}} \times 100$ (where $\mathrm{T}$ is target; $\mathrm{C}$ is control; ${ }_{\mathrm{NK}}$ is NK-cell presence; and CON is NK-cell absence).

\section{Statistical analyses}

Prism seven was used. $\mathrm{P}$ values were calculated using the paired t-test to compare cytometry analyses of patient samples before and after treatments.

\section{RESULTS}

Between December 12, 2016, and May 8, 2018, 11 patients with refractory solid cancers were treated as inpatients with the CIV-5 regimen. The most common diagnosis was colorectal cancer; the median age was 60 years, with four male and seven female patients (online supplemental table 1). Of the 11 patients, four were treated at $3 \mu \mathrm{g} /$ $\mathrm{kg}$, three at $4 \mu \mathrm{g} / \mathrm{kg}$ and four at $5 \mu \mathrm{g} / \mathrm{kg} /$ day without deaths or dose-limiting toxicities. One patient each at 3 and $5 \mu \mathrm{g} / \mathrm{kg} /$ day dose levels did not complete the first cycle due to adverse events (AEs) unrelated to CIV-5 treatment, which subsequently resolved (non-steroidal, antiinflammatory drug-induced syndrome of inappropriate antidiuretic hormone secretion and suspected septic or crystal arthritis, respectively) (table 1). These two patients were replaced. The most common AEs were similar to those observed for the CIV-10 regimen and included fever, chills, fatigue, nausea, transient liver function abnormalities, anemia, and thrombocytopenia (table 1). Patients receiving $5 \mu \mathrm{g} / \mathrm{kg} /$ day had transient decreases in oxygenation from pulmonary capillary leak syndrome. The $4 \mu \mathrm{g} /$ $\mathrm{kg}$ dose level was the optimal treatment regimen used in subsequent trials.

\section{Clinical response to treatment}

Spider plot (figure 4) of 8 of 11 patients' response to therapy as assessed by RECIST V.1.1 criteria: stable disease was the best observed response. Three patients fulfilled the criteria of $\geq 15 \%$ decrease in measurable disease required to receive treatment beyond cycle 2 .

\section{Lymphocyte response to treatment}

Previously, we demonstrated that IVB treatment with rhIL-15 resulted in acute lymphocytopenia, followed by hyperproliferation of cells with an increase in NK and $\mathrm{CD}^{+} \mathrm{T}$ cells. Here we show that the administration of rhIL-15 by CIV had an even greater impact on $\mathrm{CD} 8^{+}$ $\mathrm{T}$ and NK, particularly CD56 bright NK-cell expansions (figure 5 and table 2). As expected, all patients experienced generalized acute lymphocytopenia at the initiation of treatment. Following this, the blood lymphocytes numbers returned to baseline with evidence of high levels of proliferation lasting through the end of treatment. Changes were maximal 3 days following treatment cessation but were still dramatic 10 days later.

\section{Assessment of anti-rhIL-15 antibodies}

Patients were assessed for the development of anti-IL-15 antibodies in serum during each treatment cycle. Immunogenicity timepoints were pre-treatment and day 21 . Testing was extended to cycle 3 , day 43 for one patient. None of the serum samples obtained from the 11 patients treated in this trial showed evidence of antibodies against IL-15. Antibodies to IL-15 were not observed on any of the previous studies involving intravenous IL-15, whereas such antibodies developed in a proportion of patients receiving more than three cycles of subcutaneous IL-15. ${ }^{3031}$

\section{Inflammatory cytokine production}

By 8 hours after the onset of infusion interferon gamma (IFN- $\gamma$ ) increased 60-fold and IL-6 increased 30-fold (online supplemental figure 2). By day 6 , soluble IL-2R $\alpha$ increased 10-fold, IL-18 to 4-fold, IL-1 $\beta$ to 2-fold and tumor necrosis factor alpha (TNF- $\alpha$ ) to 8 -fold (online supplemental figure 3).

\section{Expansions of the different lymphocyte subsets following CIV- 5 administration}

The 5-day CIV IL-15 infusions induced a maximum increase in total numbers of circulating NK cells of 21-fold to 44-fold (mean 34-fold). Detailed analyses of the two major NK subsets showed higher effects in the expansions of the CD56 $6^{\text {bright }}$ NK subset with an increase from 52.1-fold to 144.7-fold compared with an increase of the CD56 $6^{\mathrm{dim}}$ NK subset from 11.1-fold to 20.7-fold (figure 1A). Among T lymphocytes, $\gamma \delta \mathrm{T}$ cells were the most affected by IL-15 infusion with an increase in total numbers from 4.6-fold to 7.7-fold, followed by $\mathrm{CD} 8^{+} \mathrm{T}$ cells with increase expansions from 2.5-fold to 4.1-fold (figure 3A). Treatments had lesser effects on the $\mathrm{CD} 4^{+}$ T-cell subset that increased in total numbers by 1.2-fold to 2.4-fold. Those discrepancies between expansions of the different lymphocytes subsets were supported by evaluation of expressions of the proliferation marker, Ki- 67 , showing that between $80 \%$ and $90 \%$ of NK cells, $70 \%$ of $\gamma \delta \mathrm{T}$ cells, $45 \%$ of $\mathrm{CD}^{+} \mathrm{T}$ cells and $25 \%$ of $\mathrm{CD}^{+}$cells had proliferated 3 days following cessation of treatment (figure 1A). There was no statistical difference observed among the three different doses of IL-15 (figures 1-3).

\section{Phenotypical changes of NK-cell subpopulations after CIV}

To examine whether IL-15 treatments induce phenotypical changes that could affect gain and/or loss in functions in NK cells, we used two distinct panels of antibodies targeting the main receptors known to drive activation and inhibition or exhaustion of NK cells. Expression of those receptors were evaluated on both NK CD56 $6^{\text {bright }}$ and CD56 $6^{\text {dim }}$ NK-cell subsets prior to and 3 days after cessation of IL-15 infusions using PBMCs obtained from nine patients (three patients for each 
Table 1 Clinical adverse events and laboratory a(bnormalities possibly, probably or definitely related to research (5-day CIV cohort) excluding single grade 1 events

\begin{tabular}{|c|c|c|c|c|c|c|c|c|c|c|c|c|}
\hline \multirow[b]{2}{*}{ СтC V4 grade } & \multicolumn{4}{|c|}{$3 \mu \mathrm{g} / \mathrm{kg}, \mathrm{n}=4$} & \multicolumn{4}{|c|}{$4 \mu \mathrm{g} / \mathrm{kg}, \mathrm{n}=3$} & \multicolumn{4}{|c|}{$5 \mu \mathrm{g} / \mathrm{kg}, \mathrm{n}=4$} \\
\hline & 1 & 2 & 3 & 4 & 1 & 2 & 3 & 4 & 1 & 2 & 3 & 4 \\
\hline Arthritis & & & & & & 1 & & & 0 & 0 & & \\
\hline Bladder infection & & 1 & & & 0 & 0 & & & 0 & 0 & & \\
\hline Chills & 1 & 1 & & & 0 & 2 & & & 0 & 2 & & \\
\hline Constipation & 1 & 0 & & & 0 & 0 & & & 1 & 0 & & \\
\hline Diarrhea & 2 & 0 & & & 1 & 0 & & & 1 & 1 & & \\
\hline Dizziness & & & & & 2 & 0 & & & 0 & 0 & & \\
\hline Dry mouth & 1 & 0 & & & 2 & 0 & & & 0 & 0 & & \\
\hline Dry skin & & & & & 0 & 1 & & & 0 & 0 & & \\
\hline Edema limbs & 1 & 1 & & & 0 & 0 & & & 0 & 0 & & \\
\hline Fatigue & 1 & 1 & & & 0 & 0 & & & 2 & 1 & & \\
\hline Fever & 2 & 2 & & & 1 & 1 & & & 2 & 2 & & \\
\hline Headache & 1 & 0 & & & 1 & 0 & & & 0 & 0 & & \\
\hline Hypotension & & 1 & & & & 1 & & & 1 & & & \\
\hline Nausea & 2 & 0 & & & 2 & 0 & & & 3 & 0 & & \\
\hline Pulmonary edema & & 1 & & & & & & & & & & \\
\hline Rash maculopapular & 2 & 0 & & & 0 & 0 & & & 2 & 0 & & \\
\hline Vomiting & 2 & 0 & & & 1 & 0 & & & 2 & 0 & & \\
\hline Anemia & & & 2 & & & 2 & & & 1 & 1 & 1 & \\
\hline ALT increased & 1 & 1 & 0 & & 1 & 1 & 0 & 0 & 3 & 0 & 0 & \\
\hline AST increased & & 2 & 0 & & 2 & 0 & 0 & 0 & 4 & 0 & 0 & \\
\hline Alkaline phosphatase & & 1 & 0 & & 1 & 0 & 1 & 0 & 2 & 1 & 0 & \\
\hline Hyperbilirubinemia & 1 & 1 & 0 & & 0 & 1 & 0 & 0 & 1 & 0 & 1 & \\
\hline Hypoalbuminemia & & 2 & 0 & & 1 & 1 & 0 & 0 & 2 & 2 & 0 & \\
\hline Creatinine increased & & & & & 1 & 0 & 0 & 0 & 1 & 2 & 0 & \\
\hline Hyperglycemia & & & & & & & & & & 1 & & \\
\hline Hypernatremia & 2 & 0 & 0 & & 0 & 0 & 0 & 0 & & 0 & 1 & \\
\hline Hyponatremia & 1 & 0 & 1 & & 2 & 0 & 0 & 0 & 3 & 0 & 0 & \\
\hline Hypocalcemia & 1 & 0 & 0 & & 1 & 0 & 0 & 0 & 4 & 0 & 0 & \\
\hline Hypokalemia & 2 & 1 & 0 & & 0 & 0 & 0 & 0 & 1 & 0 & 2 & \\
\hline Hypomagnesemia & & & & & 1 & 0 & 0 & 0 & 3 & 0 & 0 & \\
\hline Hypophosphatemia & & 1 & 2 & & 0 & 2 & 0 & 0 & 0 & 1 & 2 & \\
\hline Lymphocytosis & & & & 2 & 0 & 0 & 0 & 2 & 0 & 0 & 1 & 2 \\
\hline Lymphopenia & & 1 & 0 & & 0 & 1 & 1 & 0 & 0 & 2 & 1 & 1 \\
\hline Neutropenia & 1 & 0 & 0 & & 1 & 0 & 1 & 0 & 0 & 1 & 0 & \\
\hline Thrombocytopenia & & 2 & 0 & & 2 & 0 & 0 & 0 & 1 & 1 & 0 & \\
\hline Leukopenia & & 2 & 0 & & 0 & 1 & 1 & 0 & 1 & 1 & 1 & \\
\hline
\end{tabular}

ALT, alanine aminotransferase; AST, aspartate aminotransferase; CIV, continuous intravenous infusion.

of the three doses of IL-15 tested, figure 1B). Looking at the mean fluorescence intensity of the major activating receptors expressed by NK cells (figure 1B, left), we observed changes within the $\operatorname{CD} 56^{\text {dim }}$ population with increases in expression of NKp46, NKp30, natural killer group 2D (NKG2D) and CD122. Augmentation of cell-surface expression of NKG2D (CD314), CD122 and DNAM-1 (CD226) was detected in CD56 $6^{\text {bright }}$ cells. Levels of CD16 expression were not affected by treatment of both NK subsets. None of the activating receptors 


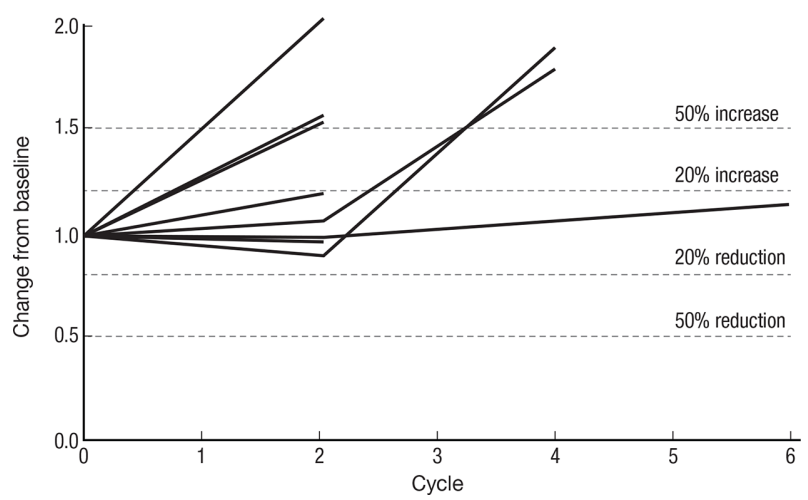

Figure 4 Spider plot of CIV IL-15 treatment spider plot of 8 of 11 treated patients who had at least one restaging CT scan, showing changes from baseline in tumor burden ( $Y$ axis) measured as the product of the longest diameters of solid metastatic target lesions of $>1 \mathrm{~cm}$ on high-resolution CT scans (shortest diameter for lymph nodes) assessed at the end of every CIV rhIL-15 cycle (X-axis). Above the $20 \%$ increase, dashed line indicates progressive disease by RECIST criteria and below 30\% reduction indicates partial response. Patients who had stable disease after their first two cycles of treatment continued to be restaged at regular intervals even though their treatment had been stopped. CIV, continuous intravenous infusion; IL, interleukin.

studied showed decreased expressions after IL-15 infusions. Surface proteins involved in inhibition or exhaustion of NK cells were presented as percentages of each NK subset (figure 1B, right). After IL-15 infusions, the percentages of T-cell immunoreceptor with Ig and ITIM domains (TIGIT) cells appeared to be differentially regulated between the two NK subpopulations since their proportions were decreased among CD56 $6^{\text {bright }}$ cells and increased within CD56 $6^{\mathrm{dim}}$ cells. IL-15 treatments notably decreased percentages of T-cell immunoglobulin and

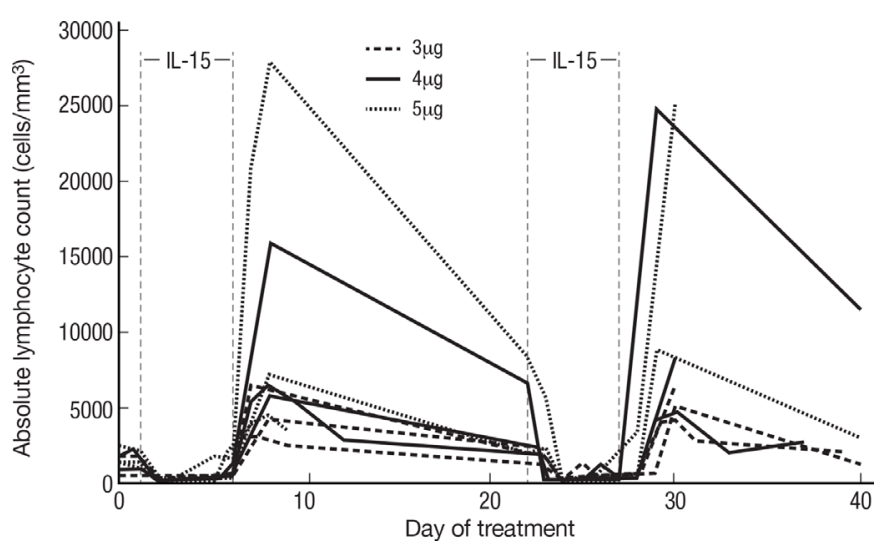

Figure 5 Increase in lymphocytes predominantly NKcell count during continuous infusion of rhlL-15 IL-15 was administered at progressively increasing doses of 3 , 4 and $5 \mu \mathrm{g} / \mathrm{kg} /$ day by 5 -day CIV infusion to patients with metastatic malignancy. Three days following termination of the treatment, there was a dramatic 34-fold mean increase in the number of circulating lymphocytes, predominantly NKcell counts, and in the $4 \mu \mathrm{g} / \mathrm{kg} /$ day cohort 144-fold increase in the number of circulating CD56 $6^{\text {bright }}$ NK cells. IL, interleukin; NK, natural killer; rhlL, recombinant human interleukin-15. mucin domain containing $3^{+}$cells in both NK subsets and of lymphocyte-activation gene $3^{+}$cells in CD56 $6^{\mathrm{dim}}$ subpopulation. Proportions of cytotoxic T-lymphocyte-associated protein (CTLA-4)+ and NKG2A ${ }^{+}$were not affected by IL-15 infusions in both NK-cell subpopulations. Together, those data suggest that IL-15 treatments favor NK-cell activation since infusions lead mainly to upregulation of receptors involved in NK-cell activation. There were no dose-dependent differences in the outcomes observed.

\section{IL-15 infusions enhanced cytokine production by NK, CD8 ${ }^{+}$ and $\mathrm{CD4}^{+} \mathrm{T}$ cells}

To monitor effects of IL-15 infusions on cytokine secretions by NK cells, we used ex vivo stimulation with IL-12 and IL-18 to detect intracellular production of IFN- $\gamma$, TNF- $\alpha$ and granulocyte-macrophage colony-stimulating factor (GM-CSF) in both NK subsets (figure 2A). Both NK subpopulations produced mainly IFN- $\gamma$ prior to treatment. After infusions, percentages of CD56 $6^{\text {bright }}$ secreting IFN- $\gamma$ increased from $50 \%$ to $80 \%$ in two distinct populations; one subpopulation secreted all three cytokines, IFN $\gamma$, TNF- $\alpha$ and GM-CSF increasing from below $2 \%$ to $25 \%$ after treatment, whereas the second population, augmenting from below $5 \%$ to $30 \%$ after CIV-5, produced only IFN- $\gamma$ and GM-CSF. For the CD56 $6^{\operatorname{dim}}$ subset, only percentages of cells producing IFN- $\gamma$ alone increased after IL-15 infusions from $35 \%$ to $70 \%$.

T-cell subpopulations $\left(\mathrm{CD}^{+}, \mathrm{CD}^{+}\right.$, and $\left.\gamma \delta\right)$ were assayed for TNF- $\alpha$, IFN- $\gamma$, and IL-2 production following PMA/ionomycin stimulation (figure 3B). Both $\mathrm{CD}^{+}$and $\mathrm{CD}^{+} \mathrm{T}$ cells gained mainly in their abilities to produce TNF- $\alpha$. No change was observed for the $\gamma \delta$ T cells.

\section{II-15 administration increased the cytotoxic functions of both NK-cell subsets}

The IL-15 infusions improved cytotoxic functions of total NK cells when lytic activities were compared among the same numbers of total NK cells pretreatment and posttreatment at an effector to target ratio of 5:1 using three different target cells, involving for their killing different activating receptors: C1R-MICA (figure 2B, top row), K562 (figure 2B, middle) and anti-CD20-coated Raji cells (figure 2B, bottom) recognized by NK cells via NKG2D, natural cytotoxic receptors (NKp30 and NKp46) and CD16-mediated ADCC, respectively. Degranulation via CD107 detection and IFN- $\gamma$ production were assessed in CD56 $6^{\text {bright }}$ (figure 2B, middle column), and in CD56 ${ }^{\text {dim }}$ (right column) subsets after stimulation with the same target cells described previously at an effector to target ratio of 2:1. Within the CD56 $6^{\text {bright }}$ NK cells, CIV-5 promoted cells that had the abilities to degranulate and produce IFN- $\alpha$ at the same time, whereas CD56 ${ }^{\text {dim }}$ NK cells gained mainly in degranulation on target recognition.

Degranulation via CD107 detection and IFN- $\gamma$ production were simultaneously assessed in $\mathrm{CD} 56^{\text {bright }}$ (figure 2B, middle column) and in $\mathrm{CD} 56^{\mathrm{dim}}$ (figure 2B, right column) subsets after stimulation with the same target cells described earlier at an effector to target ratio 


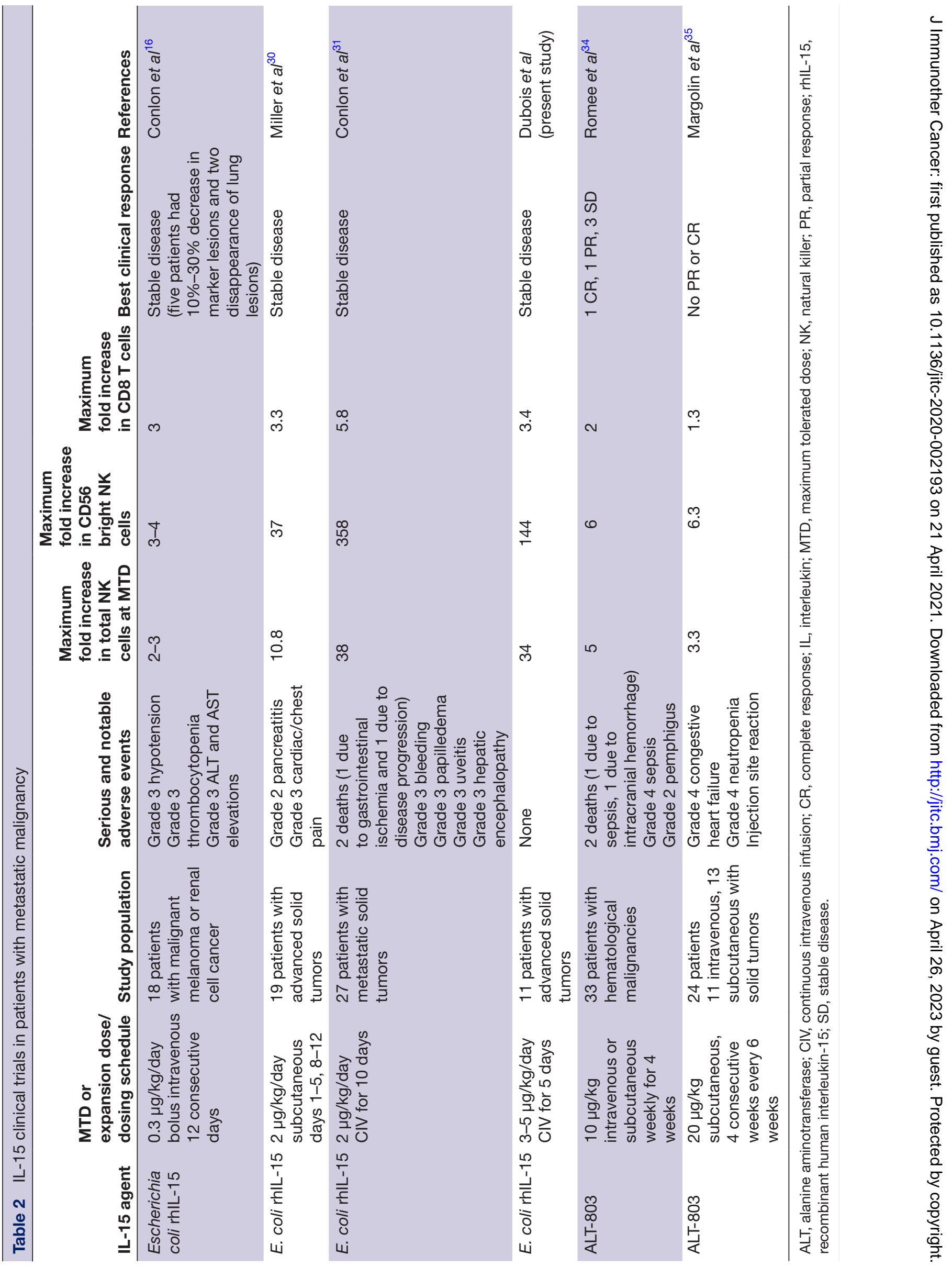


of 2:1. In response to the three targets, we observed that CIV-5 promoted CD56 $6^{\text {bright }}$ NK subset to degranulate and produce IFN- $\gamma$ at the same time, whereas CD56dim NK-cell subset gained mainly in degranulation. Phenotypical analyses revealed increased percentages of cells expressing TIGIT within the CD56 ${ }^{\mathrm{dim}}$ NK subpopulation after IL-15 treatment. Since TIGIT is known to attenuate cytotoxicity of NK cells, we compared degranulation abilities of TIGIT $^{+}$and TIGIT $^{-}$among CD56 ${ }^{\text {dim }}$ subsets prior and after CIV-5 on stimulation with target cells expressing or not TIGIT ligand, CD155 (using CD155 K562 cells vs CD155- Raji cells, figure 2C). Percentages of $\mathrm{CD}_{107^{+}}$among TIGIT $^{+} \mathrm{CD} 56^{\mathrm{dim}}$ subsets were lower than among TIGIT $^{-}$CD56 $6^{\text {dim }}$ subsets following stimulation with $\mathrm{CD} 155^{+}$target cells. However, degranulation was augmented after IL-15 infusions despite TIGIT-mediated inhibition.

Taken together, the short 5-day course of rhIL-15 given as a continuous infusion led to massive expansion of NK-cell numbers. After the termination of IL-15 infusions, both NK-cell subsets showed vigorous proliferation, increased cytokine production abilities and effective cytotoxic functions involving the major activating receptors. Augmentation in total numbers of $\mathrm{CD} 8^{+} \mathrm{T}$ cells and NK cells with gain in their cytotoxic functions supports ongoing trials of CIV-5 IL-15 with anticancer monoclonal antibodies to increase their efficacy via ADCG as antitumor antibodies.

\section{DISCUSSION}

IL-15 plays a pivotal stimulatory role in the differentiation and proliferation of $\mathrm{NK}$ and $\mathrm{CD} 8^{+} \mathrm{T}$ cells. Preclinical data demonstrated considerable potential of IL-15 as an immunotherapeutic for cancer; by translating these observations into the clinic, over 170 clinical trials have been initiated in the treatment of cancer with different IL-15 preparations. ${ }^{15}$ Compared with other treatment regimens or formulations of IL-15, the CIV-5 or CIV-10 regimens resulted in the greatest increase in circulating effector cells (table 2). ${ }^{15} 163034-36$ There have been extensive efforts to develop potent long-acting IL-15 agonists, including ALT-803 (N-803, IL-15, N72D linked to the sushi domain of IL-15R $\alpha$ IgG Fc fusion protein). ${ }^{34-36}$ However, due to pharmacokinetic disadvantages these preparations do not supply sufficient steady state serum levels of IL-15 that are consistent with their less significant effects on $\mathrm{NK}$ and $\mathrm{CD} 8^{+} \mathrm{T}$-cell expansions. A large proportion of subcutaneous injected drug may not reach the systemic circulation due to local consumption by both activated $\alpha \beta$ and $\gamma \delta$ T cells at the site of injection, resulting in characteristic injection site reactions which can be up to $30 \mathrm{~cm}$ in diameter. ${ }^{34}$ There is with ALT-803 only a bioavailability of $3 \%$ indicating $~ 97 \%$ of the dose not reaching the systemic circulation. This represents a significant drawback despite the ease of administration and the weekly treatment schedule. As a consequence of the low bioavailability, ALT- 803 at $10 \mu \mathrm{g} / \mathrm{kg} /$ day by subcutaneous injection yielded only a twofold increase in the number of $\mathrm{CD}^{+} \mathrm{T}$ cells and only a fivefold and sixfold increase in the number of NK and CD5 $6^{\text {bright }} \mathrm{NK}$ cells, respectively. ${ }^{34}$ This, as noted in table 2 , contrasts with the 3.8-fold increase in the number of $\mathrm{CD}^{+} \mathrm{T}$ cells, 34-fold increase in the number of NK cells, and up to 144-fold increase in the number of CD56 $6^{\text {bright }}$ NK cells observed by CIV-5 of IL-15. CIV-5 gave comparable efficacy with CIV-10. It would clearly be of value to evaluate whether yet shorter infusions with CIV-1, CIV-2 or CIV-3 are efficacious since this would dramatically increase patient and physician acceptability and facilitate the studies, especially if multiple cycles are envisioned. Thus, IL-15 by CIV-5 or CIV-10 was the most successful among the different IL-15 preparations in inducing the maximal increase in the numbers of $\mathrm{CD}^{+} \mathrm{T}$ cells, NK cells and CD56 $6^{\text {bright }}$ NK cells. Felices and coworkers, studying purified NK cells in vitro suggested that continuous treatment with IL-15 exhausts such purified NK cells resulting in decreased viability and a cell cycle arrest gene expression pattern. ${ }^{37}$ Furthermore, they proposed that these findings should inform IL-15 dosing strategies. Frutoso and Mortier, ${ }^{17}$ and Frutoso and coworkers ${ }^{38}$ provide excellent reviews of 'NK cell hyporesponsiveness: more is not always better'. They outline circumstances where providing additional IL-15 could actually be counterproductive and could lead to NK-cell hyporesponsiveness. Furthermore, our group demonstrated hyporesponsiveness when there are repeated cycles of IL-15 in less than 3-week intervals. Our clinical trials using continuous IL-15 infusions in vivo demonstrated that continuous IL-15 treatments led to massive NK-cell proliferations as shown with Ki-67 expression in more than $80 \%$ of NK cells at termination of 5-day IL-15 CIV. Both NK subsets after treatment gained in expressions of some activating receptors. Moreover, lytic capacities of both NK subsets after IL-15 infusions were effectively increased in killing of target cells recognized by three major types of activating receptors triggering NK cytotoxic activities. Finally, both CIV trials showed that NK cells significantly gained in cytokine release functions. In conclusion, our data support the view that continuous IL-15 treatments in vivo for 5 or 10 days result in extensive expansions and gain of functions of NK cells rather than their exhaustion. The discrepancy between our studies and the work of Felices and coworkers may reflect overgrowth and decreases in nutriments in the 'in vitro setup' of purified NK cells versus our examination of NK cells continuously stimulated with fresh IL-15 in vivo. Additionally, other factors are absent in culture, in particular interaction between NK cells and other cell types, such as monocytes/macrophages and dendritic cells known to support NK functions. ${ }^{27}$

Although diverse forms of IL-15 monotherapy augment the number of circulating NK and $\mathrm{CD} 8^{+} \mathrm{T}$ cells, monotherapy trials with any of the treatment strategies/or agents did not demonstrate clinical activity, with the sole exception being postallogeneic stem cell transplant patients who possessed an underlying graft versus 
leukemic capacity. ${ }^{34}$ There are a variety of explanations possible for this lack of efficacy, including induction of immunological checkpoints and lack of significant targeting of these effector cells to sites of tumor. An attractive strategy that exploits the NK target cell expansion would be to use IL-15 in association with anticancer monoclonal antibodies to target the NK cells to the tumor, to increase ADCC and effector action on cancer cells. IL-15 preparations have been reported to be of value in combination with in vivo administered monoclonal antibodies. ${ }^{39-43}$ Our preclinical experiments with IL-15 and rituximab in a syngeneic mouse model of the EL4 lymphoma transfected with human CD20 and alemtuzumab (CAMPATH-1H) in a xenograft model of human adult T-cell leukemia ${ }^{27}$ showed that IL-15 enhanced therapeutic efficacy of both antibodies.

In conclusion, the short duration CIV-5 rhIL-15 regimen and its safety profile may make outpatient administration via an ambulatory infusion pump feasible. The massive expansion of NK cells and increases in $\mathrm{CD}^{+} \mathrm{T}$ cells it produced were much greater than with other non-CIV IL-15 regimens. Since NK cells are key mediators of ADCC, we have opened trials administering CIV IL-15 with antibodies, obinutuzumab (NCT03759184), avelumab (NCT03905135), mogamulizumab (NCT04185220) and alemtuzumab (NCT02689453) that may benefit from IL-15-induced expansion and gain in functions of NK cells to augment their antitumor ADCC and antitumor efficacy.

\section{Author affiliations}

${ }^{1}$ Lymphoid Malignancies Branch, Center for Cancer Research, National Cancer Institute, Bethesda, Maryland, USA

${ }^{2}$ Department of Laboratory Medicine, NIH Clinical Center, Bethesda, Maryland, USA ${ }^{3}$ Laboratory of Pathology, Center for Cancer Research, National Cancer Institute, Bethesda, Maryland, USA

${ }^{4}$ Center for Biologics Evaluation and Research (CBER), US Food and Drug Administration, Silver Spring, Maryland, USA

${ }^{5}$ Biometric Research Program, Division of Cancer Treatment and Diagnosis, Center for Cancer Research, National Cancer Institute, Bethesda, Maryland, USA

Contributors Conception and design: KCC, MDM, SD, and TAW. Acquisition of data: SD, KCC, MDM, TAF, SP, BRB, and MNP. Analysis and interpretation of data: SD, MDM, KCC, TAW, JHS, BRB, and JRM. Provision of study materials or patients: $\mathrm{KCC}, \mathrm{JH}-\mathrm{A}, \mathrm{LPP}$, and MDM. All authors reviewed and approved the manuscript for publication prior to submission.

Funding This study was supported by the Intramural Research Program of the National Cancer Institute, National Institutes of Health.

Competing interests None declared.

Patient consent for publication Not required.

Ethics approval The study was approved by the institutional review board of the National Cancer Institute and was performed in accordance with the ethical guidelines of the Declaration of Helsinki, Ethical Principles of Medical Research. All patients signed a written informed consent to participate in the clinical trial.

Provenance and peer review Not commissioned; externally peer reviewed.

Data availability statement Data are available upon reasonable request. Tabulated data will be posted on clinicaltrials.gov. Deidentified patient data and clinical trial protocol available by request from corresponding author.

Supplemental material This content has been supplied by the author(s). It has not been vetted by BMJ Publishing Group Limited (BMJ) and may not have been peer-reviewed. Any opinions or recommendations discussed are solely those of the author(s) and are not endorsed by BMJ. BMJ disclaims all liability and responsibility arising from any reliance placed on the content. Where the content includes any translated material, BMJ does not warrant the accuracy and reliability of the translations (including but not limited to local regulations, clinical guidelines, terminology, drug names and drug dosages), and is not responsible for any error and/or omissions arising from translation and adaptation or otherwise.

Open access This is an open access article distributed in accordance with the Creative Commons Attribution Non Commercial (CC BY-NC 4.0) license, which permits others to distribute, remix, adapt, build upon this work non-commercially, and license their derivative works on different terms, provided the original work is properly cited, appropriate credit is given, any changes made indicated, and the use is non-commercial. See http://creativecommons.org/licenses/by-nc/4.0/.

\section{ORCID iDs}

Thomas A Waldmann http://orcid.org/0000-0003-4500-6660

Kevin C Conlon http://orcid.org/0000-0002-4118-7524

\section{REFERENCES}

1 Choudhury M, Efros M, Mittelman A. Interferons and interleukins in metastatic renal cell carcinoma. Urology 1993;41:67-72.

2 Rosenberg SA. II-2: the first effective immunotherapy for human cancer. J Immunol 2014;192:5451-8.

3 Waldmann TA. Cytokines in cancer immunotherapy. In: Leonard WJ, Schreiber RD, eds. Cytokines from basic mechanisms of cellular control to new therapeutics. Spring Harbor, NY: Cold Spring Harbor Laboratory Press, 2018: 10. a028472-53.

4 Waldmann TA. The biology of interleukin-2 and interleukin-15: implications for cancer therapy and vaccine design. Nat Rev Immunol 2006;6:595-601.

5 Dubois S, Mariner J, Waldmann TA, et al. II-15Ralpha recycles and presents IL-15 in trans to neighboring cells. Immunity 2002;17:537-47.

6 Sato N, Patel HJ, Waldmann TA, et al. The IL-15/IL-15Ralpha on cell surfaces enables sustained IL-15 activity and contributes to the long survival of CD8 memory T cells. Proc Natl Acad Sci U S A 2007;104:588-93.

7 Lu J, Giuntoli RL, Omiya R, et al. Interleukin 15 promotes antigenindependent in vitro expansion and long-term survival of antitumor cytotoxic T lymphocytes. Clin Cancer Res 2002;8:3877-84.

8 Benito-Miguel M, García-Carmona Y, Balsa A, et al. A dual action of rheumatoid arthritis synovial fibroblast IL-15 expression on the equilibrium between $\mathrm{CD} 4^{+} \mathrm{CD} 25^{+}$regulatory $\mathrm{T}$ cells and $\mathrm{CD} 4^{+} \mathrm{CD} 25$ Responder T cells. J Immunol 2009;183:8268-79.

9 Kinter AL, Godbout EJ, McNally JP, et al. The common gammachain cytokines IL-2, IL-7, IL-15, and IL-21 induce the expression of programmed death-1 and its ligands. J Immunol 2008;181:6738-46.

10 Zeng R, Spolski R, Finkelstein SE, et al. Synergy of IL-21 and $\mathrm{IL}-15$ in regulating $\mathrm{CD} 8^{+} \mathrm{T}$ cell expansion and function. $J$ Exp Med 2005;201:139-48.

11 Kobayashi H, Dubois S, Sato N, et al. Role of trans-cellular IL-15 presentation in the activation of NK cell-mediated killing, which leads to enhanced tumor immunosurveillance. Blood 2005;105:721-7.

12 Munger W, DeJoy SQ, Jeyaseelan R, et al. Studies evaluating the antitumor activity and toxicity of interleukin-15, a new $T$ cell growth factor: comparison with interleukin-2. Cell Immunol 1995;165:289-93.

13 Evans R, Fuller JA, Christianson G, et al. II-15 mediates anti-tumor effects after cyclophosphamide injection of tumor-bearing mice and enhances adoptive immunotherapy: the potential role of NK cell subpopulations. Cell Immunol 1997;179:66-73.

14 Fehniger TA, Caligiuri MA. Interleukin 15: biology and relevance to human disease. Blood 2001;97:14-32.

15 Waldmann TA, Miljkovic MD, Conlon KC. Interleukin-15 (dys) regulation of lymphoid homeostasis: Implications for therapy of autoimmunity and cancer. J Exp Med 2020;217:e20191062.

16 Conlon KC, Lugli E, Welles HC, et al. Redistribution, hyperproliferation, activation of natural killer cells and CD8 T cells, and cytokine production during first-in-human clinical trial of recombinant human interleukin-15 in patients with cancer. J Clin Oncol 2015;33:74-82.

17 Frutoso M, Mortier E. Nk cell hyporesponsiveness: more is not always better. Int J Mol Sci 2019;20:4514.

18 Fehniger TA, Cooper MA, Caligiuri MA. Interleukin-2 and interleukin-15: immunotherapy for cancer. Cytokine Growth Factor Rev 2002;13:169-83. 
19 Ma A, Koka R, Burkett P. Diverse functions of IL-2, IL-15, and IL-7 in Iymphoid homeostasis. Annu Rev Immunol 2006;24:657-79.

20 Steel JC, Waldmann TA, Morris JC. Interleukin-15 biology and its therapeutic implications in cancer. Trends Pharmacol Sci 2012;33:35-41.

21 Castillo EF, Schluns KS. Regulating the immune system via IL-15 transpresentation. Cytokine 2012;59:479-90.

22 Huntington ND, Legrand N, Alves NL, et al. II-15 trans-presentation promotes human NK cell development and differentiation in vivo. $J$ Exp Med 2009;206:25-34.

23 Schluns KS, Klonowski KD, Lefrançois L. Transregulation of memory CD8 T-cell proliferation by IL-15Ralpha+ bone marrow-derived cells. Blood 2004;103:988-94.

24 Marks-Konczalik J, Dubois S, Losi JM, et al. II-2-Induced activationinduced cell death is inhibited in IL-15 transgenic mice. Proc Natl Acad Sci U S A 2000;97:11445-50.

25 Yu P, Steel JC, Zhang M, et al. Simultaneous inhibition of two regulatory T-cell subsets enhanced interleukin-15 efficacy in a prostate tumor model. Proc Natl Acad Sci U S A 2012;109:6187-92.

26 Yu P, Steel JC, Zhang M, et al. Simultaneous blockade of multiple immune system inhibitory checkpoints enhances antitumor activity mediated by interleukin-15 in a murine metastatic colon carcinoma model. Clin Cancer Res 2010;16:6019-28.

27 Zhang M, Wen B, Anton OM, et al. II-15 enhanced antibodydependent cellular cytotoxicity mediated by NK cells and macrophages. Proc Natl Acad Sci U S A 2018;115:E10915-24.

28 Zhang M, Yao Z, Dubois S, et al. Interleukin-15 combined with an anti-CD40 antibody provides enhanced therapeutic efficacy for murine models of colon cancer. Proc Natl Acad Sci U S A 2009;106:7513-8.

29 Klebanoff CA, Finkelstein SE, Surman DR, et al. II-15 enhances the in vivo antitumor activity of tumor-reactive CD8+ T cells. Proc Natl Acad Sci U S A 2004;101:1969-74.

30 Miller JS, Morishima C, McNeel DG, et al. A first-in-human phase I study of subcutaneous outpatient recombinant human IL15 (rhIL15) in adults with advanced solid tumors. Clin Cancer Res 2018;24:1525-35.

31 Conlon KC, Potter EL, Pittaluga S, et al. Il15 by continuous intravenous infusion to adult patients with solid tumors in a phase I trial induced dramatic NK-cell subset expansion. Clin Cancer Res 2019;25:4945-54.
32 Eisenhauer EA, Therasse P, Bogaerts J, et al. New response evaluation criteria in solid tumours: revised RECIST guideline (version 1.1). Eur J Cancer 2009;45:228-47.

33 Dubois S, Conlon KC, Müller JR, et al. IL15 Infusion of Cancer Patients Expands the Subpopulation of Cytotoxic CD56 ${ }^{\text {bright }}$ NK Cells and Increases NK-Cell Cytokine Release Capabilities. Cancer Immunol Res 2017;5:929-38.

34 Romee R, Cooley S, Berrien-Elliott MM, et al. First-In-Human phase 1 clinical study of the IL-15 superagonist complex ALT-803 to treat relapse after transplantation. Blood 2018;131:2515-27.

35 Margolin K, Morishima C, Velcheti V, et al. Phase I trial of ALT-803, a novel recombinant IL15 complex, in patients with advanced solid tumors. Clin Cancer Res 2018;24:5552-61.

36 Wrangle JM, Velcheti V, Patel MR, et al. ALT-803, an IL-15 superagonist, in combination with nivolumab in patients with metastatic non-small cell lung cancer: a non-randomised, openlabel, phase 1B trial. Lancet Oncol 2018;19:694-704.

37 Felices M, Lenvik AJ, McElmurry R, et al. Continuous treatment with IL-15 exhausts human NK cells via a metabolic defect. JCI Insight 2018;3:e96219. doi:10.1172/jci.insight.96219

38 Frutoso M, Morisseau S, Tamzalit F, et al. Emergence of NK cell hyporesponsiveness after two IL-15 stimulation cycles. J Immunol 2018;201:493-506.

39 Moga E, Cantó E, Vidal S, et al. Interleukin-15 enhances rituximabdependent cytotoxicity against chronic lymphocytic leukemia cells and overcomes transforming growth factor beta-mediated immunosuppression. Exp Hematol 2011;39:1064-71.

40 Chen X, Liu B, Han K, et al. Combination therapy of an IL-15 superagonist complex, ALT-803, and a tumor targeting monoclonal antibody promotes direct antitumor activity and protective vaccinal effect in a syngenic mouse melanoma model. $\mathrm{J}$ Immunother Cancer 2015;3:P347.

41 Liu B, Kong L, Han K, et al. A novel fusion of ALT-803 (interleukin (IL)-15 superagonist) with an antibody demonstrates antigen-specific antitumor responses. J Biol Chem 2016;291:23869-81.

42 Ochoa MC, Minute L, López A, et al. Enhancement of antibodydependent cellular cytotoxicity of cetuximab by a chimeric protein encompassing interleukin-15. Oncoimmunology 2017a;7:e1393597.

43 Ochoa MC, Minute L, Rodriguez I, et al. Antibody-dependent cel cytotoxicity: immunotherapy strategies enhancing effector NK cells. Immunol Cell Biol 2017b;95:347-55. 